\title{
Calcitonin Gene-Related Peptide Suppresses Hair Cell Responses to Mechanical Stimulation in the Xenopus Lateral Line Organ
}

\author{
Gerald P. Bailey ${ }^{1,3}$ and William F. Sewell ${ }^{1,2}$ \\ ${ }^{1}$ Eaton-Peabody Laboratory, Department of Otolaryngology, Massachusetts Eye and Ear Infirmary, Boston, \\ Massachusetts 02114, 2Program in Neuroscience and Department of Otology and Laryngology, Harvard Medical School, \\ Boston, Massachusetts 02115, and 32Department of Pathology, Boston University School of Medicine, Boston, \\ Massachusetts 02118
}

\begin{abstract}
The presence of calcitonin gene-related peptide (CGRP) in the efferent fibers of virtually every hair cell organ studied suggests it may serve some fundamental but heretofore unknown role in control of hair cell function. We examined the effects of CGRP on spontaneous and stimulus-evoked discharge patterns in an in vitro preparation of the lateral line organ of Xenopus laevis. Discharge patterns were determined by sinusoidally displacing the cupula with a glass micropipette driven with a piezoelectric device while recording afferent fiber activity. All afferent fibers had characteristic frequencies of 16-32 Hz. Responses synchronized to cupular displacements as small as $20 \mathrm{~nm}$. CGRP suppressed responses of the lateral line organ to displacement
\end{abstract}

while increasing spontaneous discharge rate. In the presence of CGRP, stimulus-response curves were shifted $10 \mathrm{~dB}$ toward higher displacement levels. The suppression of stimulusevoked responses suggests a function for CGRP as an efferent neurotransmitter that is similar to that of cholinergic efferent transmission in other hair cell organs. The $10 \mathrm{~dB}$ shift toward larger displacements makes it comparable in magnitude with the effects of electrical stimulation of efferents in the mammalian cochlea. This suggests a significant role for CGRP in efferent modulation of the output of this mechanosensory organ.

Key words: sensory; cochlea; neurotransmitter; efferent; vestibular; calcitonin gene-related peptide; acetylcholine
The presence of calcitonin gene-related peptide (CGRP) in almost every hair-cell organ studied (Adams et al., 1987; Takeda et al., 1987; Sliwinska-Kowalska et al., 1989; Wackym et al., 1990) suggests it may serve some fundamental role in control of hair cell function. Its colocalization with acetylcholine in efferent nerve fibers (Ohno et al., 1991; Vetter et al., 1991; Roberts et al., 1994; Safieddine et al., 1997) raises the possibility that it may influence cholinergic transmission at this synapse. The principal role of these efferent nerve fibers is to modify the capability of the organ to transduce mechanical motion. Most of what is known about efferent modulation of these sensory organs is associated with the cholinergic effects of efferent activation. Despite the nearly ubiquitous presence of CGRP in inner ear efferent nerve fibers, only two actions have been described in the inner ear: an increase in spontaneous discharge rate in afferent nerve fibers innervating hair cells in the lateral line organ (Adams et al., 1987), apparently produced by an increased rate of release of transmitter from the hair cell (Sewell and Starr, 1991), and an enhancement of responses of isolated hair cells to acetylcholine (Shigemoto and Ohmori, 1990).

Similar to auditory nerve fibers, afferent fibers in the lateral line organ discharge in the absence of controlled mechanical stimulation (Harris and Milne, 1966). This is attributable to release of transmitter from the hair cell associated with activation of voltage-dependent calcium channels. These channels are con-

\footnotetext{
Received Dec. 21, 1999; revised April 14, 2000; accepted April 18, 2000.

This work was supported by a grant from the National Institute on Deafness and Other Communication Disorders.

Correspondence should be addressed to Dr. William F. Sewell, Eaton Peabody Laboratory, Massachusetts Eye and Ear Infirmary, 243 Charles Street, Boston, MA 02114. E-mail: wfs@epl.meei.harvard.edu.

Copyright (C) 2000 Society for Neuroscience $\quad 0270-6474 / 00 / 205163-07 \$ 15.00 / 0$
}

tinually activated by the resting transduction current. The general response characteristics of fibers innervating hair cells in the in vivo lateral line organ are also similar to those described for auditory nerve fibers (Elepfandt, 1988). Fibers display spontaneous discharge that is modulated by mechanical stimulation and have a characteristic frequency $(\mathrm{CF})$ to which they are most responsive.

In the Xenopus laevis lateral line organ, CGRP is present in the myelinated efferent fibers (Adams et al., 1987) that synapse on the hair cell (Görner, 1967; Shelton, 1970; Fritzsch, 1989). These efferent fibers are known to be cholinergic (Russell, 1971; Flock and Lam, 1974; Hellmann and Fritzsch, 1996), with a receptor pharmacological profile (Russell, 1971; Sewell and Starr, 1991) that suggests the presence of the $\alpha-9$ nicotinic receptor (Elgoyhen et al., 1994).

Working in vitro provided significant advantages for studying the role of CGRP in hair cell function. In addition to the precise control of peptide dosage, it permitted us to define the stimulus near the hair cell. We were able to generate very fine movements of individual cupula while simultaneously recording activity from the afferent fiber that innervated the hair cells of that particular cupula. This allowed us to obtain detailed analyses of the effects of CGRP on the transfer function between cupular displacement and afferent discharge patterns.

\section{MATERIALS AND METHODS}

Postmetamorpshic Xenopus, $\sim 2 \mathrm{~cm}$ from nose to vent (Nasco, Fort Atkinson, WI), were housed at room temperature in deionized water containing $1 \mathrm{~mm}$ added calcium chloride. Each frog was anesthetized by chilling to near $0^{\circ} \mathrm{C}$ and then decapitated. A piece of skin containing the middle lateral row of stitches was removed and placed inner surface up 
on a piece of moistened filter paper. The skin was rinsed with an artificial perilymph solution containing sodium chloride $(120 \mathrm{mM})$, potassium chloride $(3.5 \mathrm{~mm})$, calcium chloride $(1.5 \mathrm{~mm})$, and glucose $(5.5 \mathrm{~mm})$, buffered with HEPES (20 mM) and adjusted to $\mathrm{pH} 7.5$ with sodium hydroxide (total $\mathrm{Na}^{+} 130 \mathrm{~mm}$ ). Perfusion of the inner surface of the skin allowed relatively rapid diffusion (within $20 \mathrm{sec}$ ) to the basolateral surface of the sensory epithelium.

The lateral line organ comprises a series of "stitches" arranged in rows along the body wall. Each stitch contains 3-10 neuromasts, which, in turn, contain 10-30 hair cells, as well as supporting cells. Each neuromast has a cupula that projects outward into the aquatic environment. A single stitch is innervated by two large myelinated afferent fibers. Each of the afferent fibers innervates hair cells of opposing polarity. It is possible to place the whole nerve trunk on a wire electrode, destroy all branches of the nerve trunk except that to one stitch, and record activity from two single fibers. It is often possible to monitor only one of those fibers if spike amplitudes are different.

For the experiments in which only spontaneous afferent discharge was recorded, the nerve branch innervating the middle lateral row of stitches was dissected from the inner surface of the skin. Extracellular recordings were made using a silver wire electrode (Sewell and Mroz, 1987). For these experiments, activity from three adjacent stitches was monitored simultaneously to reduce the variability in discharge rate normally seen in spontaneous afferent fiber discharge over time. The observed monophasic action potentials with positive polarity were amplified 1000fold and monitored on an oscilloscope. The signal-to-noise ratio was optimized by analog filtering. A Schmitt trigger device was used to determine the occurrence of action potentials, which were counted with a microprocessor.

For experiments in which stimulus-evoked discharge was recorded, the preparation was altered to permit mechanical stimulation. All branches of the lateral line nerve but one were cut, allowing the activity from one or both fibers of a single stitch to be recorded. The skin was transferred inner surface down to a modified microscope slide that had a $100 \mu \mathrm{m}$ square perfusion groove etched into the glass. The longitudinal axis of the stitch was placed opposing the perfusion groove, secured to prevent movement, and trimmed to expose the proximal $5 \mathrm{~mm}$ of the afferent nerve fiber. The skin on the microscope slide was positioned on a Zeiss (Oberkochen, Germany) standard microscope and viewed from above (cupular side) with a $16 \times 0.32 \mathrm{NA}$ lens. Extracellular afferent fiber recording, amplification, filtering, and monitoring were performed as described above. Throughout the experiment, the outer cupular surface was kept moist by perfusion with the artificial perilymph solution at a flow rate of $0.5 \mu \mathrm{l} / \mathrm{sec}$. Artificial perilymph and dissolved CGRP were delivered to the inner synaptic surface via the perfusion groove at a flow rate of $1.2 \mu \mathrm{l} / \mathrm{sec}$. Only those preparations maintaining a spontaneous discharge rate greater than 100 spikes/min were used. Only those preparations that recovered after drug administration were considered in the analysis.

Sinusoidal stimulation of the hair cell cilia produced by movement of the cupula was accomplished with a computer-controlled bimorphic piezoelectric motor coupled to a micropipette. The glass micropipette was slowly brought toward the cupula (visible with Nomarski optics) while listening to spike discharge on a loudspeaker. A burst of discharge indicated that the micropipette had touched the cupula, whereupon the cupula typically adhered to the glass micropipette.

The frequency response characteristics of the stimulation system were determined with a photonic sensor (Angstrom Resolver by Opto-acoustic Systems) and spectrum analyzer. Calibration of displacement magnitude of the micropipette was performed by imaging the micropipette tip through a $40 \times$ water immersion objective. Displacement of the micropipette tip at different stimulus frequencies was calibrated in situ by superimposing a large number of video frames during sinusoidal stimulation. The stimulation protocol comprised a $1 \mathrm{sec}$ stimulation period, followed by a $500 \mathrm{msec}$ pause. Afferent nerve fiber responses to $10 \mathrm{such}$ cycles of stimulation and pause were used to construct poststimulus time and period histograms. Period histograms were initialized at the positive zero crossing of the stimulus voltage. The synchronization and phase of the afferent discharge to the stimulus waveform were computed from the period histograms (Johnson, 1980).

The effects of CGRP were only examined in preparations in which there was no apparent damage to the cupula (as indicated by normal sensitivity to displacement) and in which one of the spikes was significantly higher in amplitude than the other. These requirements meant that only $\sim 1$ of 10 attempts resulted in a preparation adequate for pharmacological analysis. Analysis was not performed if responses were not stable for long enough for the effects of CGRP to reverse. The results presented herein represent data from 17 animals in which these requirements were met. An additional five animals were used in analysis of normal responses.

\section{RESULTS}

\section{Responses to mechanical stimulation}

At low stimulus levels, the overall discharge rate was not altered, but the pattern of discharge was modulated so that discharge increased in one phase of the wave cycle and decreased in the opposite phase. At higher stimulus levels, discharge in the excitatory phase changed more than in the suppressive phase, leading to an overall increase in discharge rate. This pattern of response is illustrated in Figure 1 in which period histograms are presented at different stimulus levels for two representative nerve fibers.

As displacement increased, the degree of modulation also increased so that the discharge became more synchronized with the stimulus. One means of quantifying the degree of synchronization is the synchronization index (SI) (Johnson, 1980). An SI of 1 would indicate that all spikes fell into one bin in the period histogram. An SI of 0 would indicate that the spikes were evenly distributed in all of the bins. Figure 2 summarizes responses from 22 animals. SI increased sigmoidally with log displacement. The slope was $\sim 0.5$ SI units per log displacement over most of its range and saturated $40 \mathrm{~dB}$ above threshold at strengths between 0.65 and 0.9 SI. Synchronization threshold at the frequency most sensitive to displacement (CF) was near $20 \mathrm{~nm}$. The CFs of these fibers were between 16 and $32 \mathrm{~Hz}$. Slopes of the log displacement functions at frequencies off $\mathrm{CF}$ did not appear to be significantly different from those at CF. When SI neared saturation levels, overall discharge rate began to increase. The increase in discharge was represented as the discharge ratio (DR), calculated by dividing the discharge rate evoked during stimulus presentation by the spontaneous discharge rate after stimulus presentation. DR increased exponentially with the log of stimulus intensity and did not saturate at the highest levels of displacement $(32 \mu \mathrm{m})$. SI was a far more sensitive measure of responsiveness than discharge rate. From the data of Figure 2, it is evident that the displacement-rate function was less sensitive by a 30 - to 50 -fold difference.

The frequency response properties of the lateral line organ were characterized by plotting threshold displacements for both SI and DR. Tuning curves for five fibers are plotted in Figure 3. For both SI and DR, all fibers responded with highest sensitivity to stimulus frequencies between 16 to $32 \mathrm{~Hz}$. Slopes of the tuning curves at frequencies below $\mathrm{CF}$ were $8 \mathrm{~dB} /$ octave; slopes at frequencies above the $\mathrm{CF}$ were $26 \mathrm{~dB} /$ octave. Tuning curves generated using DR criteria (a change in DR of 0.25 ) were more broadly tuned and considerably less sensitive than those generated with SI criteria (SI of 0.15).

For stimulus frequencies between 1 and $8 \mathrm{~Hz}$, the phase of the response had a constant value of $0.5 \pi$ radians $\left(90^{\circ}\right)$ with respect to displacement. Above $8 \mathrm{~Hz}$, the phase changed linearly with the logarithm of the frequency from $0.5 \pi$ radians to almost $1.5 \pi$ radians $\left(270^{\circ}\right)$ at $128 \mathrm{~Hz}$, or at a change of $0.6 \pi$ radians/octave (data not shown). At these frequencies, the synaptic delay and conduction time from the synapse to the recording site $(<1 \mathrm{msec})$ made insignificant contributions to the change in phase with frequency. These results are in good agreement with those of Kroese et al. (1978), who used sinusoidal water displacements generated by a glass sphere to stimulate the lateral line organ. 

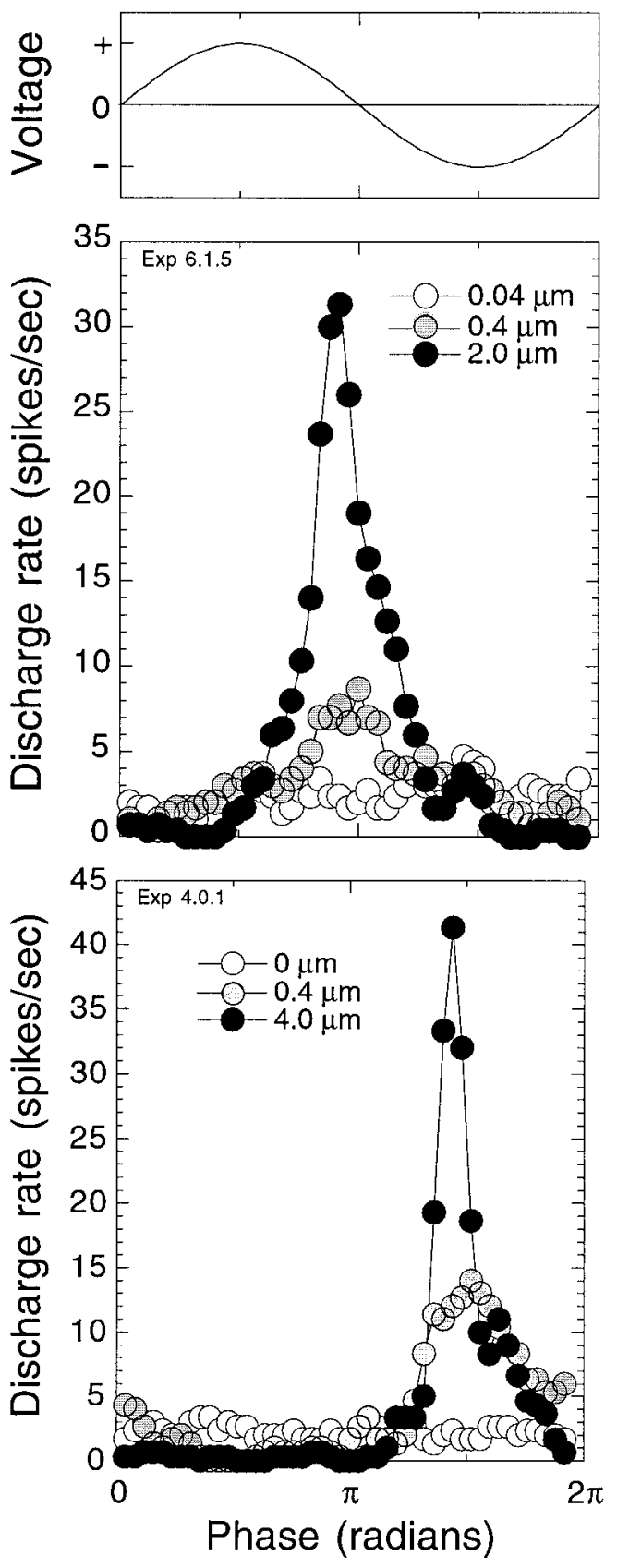

Figure 1. Afferent nerve fibers of the lateral line organ discharge synchronously to mechanical movement of the cupula. Period histograms represent 10 presentations of sinusoidal cupular displacement at the characteristic frequency of the fiber. Voltage applied to the piezoelectric device is shown in the top. The bottom panels indicate responses in two different fibers to different displacement levels. At the lowest displacement levels (open circles), responses were below the synchronization threshold of the fibers. At moderate displacement levels (filled gray circles), responses were synchronized to the stimulus waveform but below the rate threshold of the fibers. At the highest displacement levels ( filled black circles), responses evoked increases in afferent discharge.

\section{Responses to CGRP}

As described in detail in previous reports on this preparation, CGRP increased spontaneous discharge rate (Adams et al., 1987; Sewell and Starr, 1991). The increase was observed within tens of seconds of application, and the rate could stay increased for tens
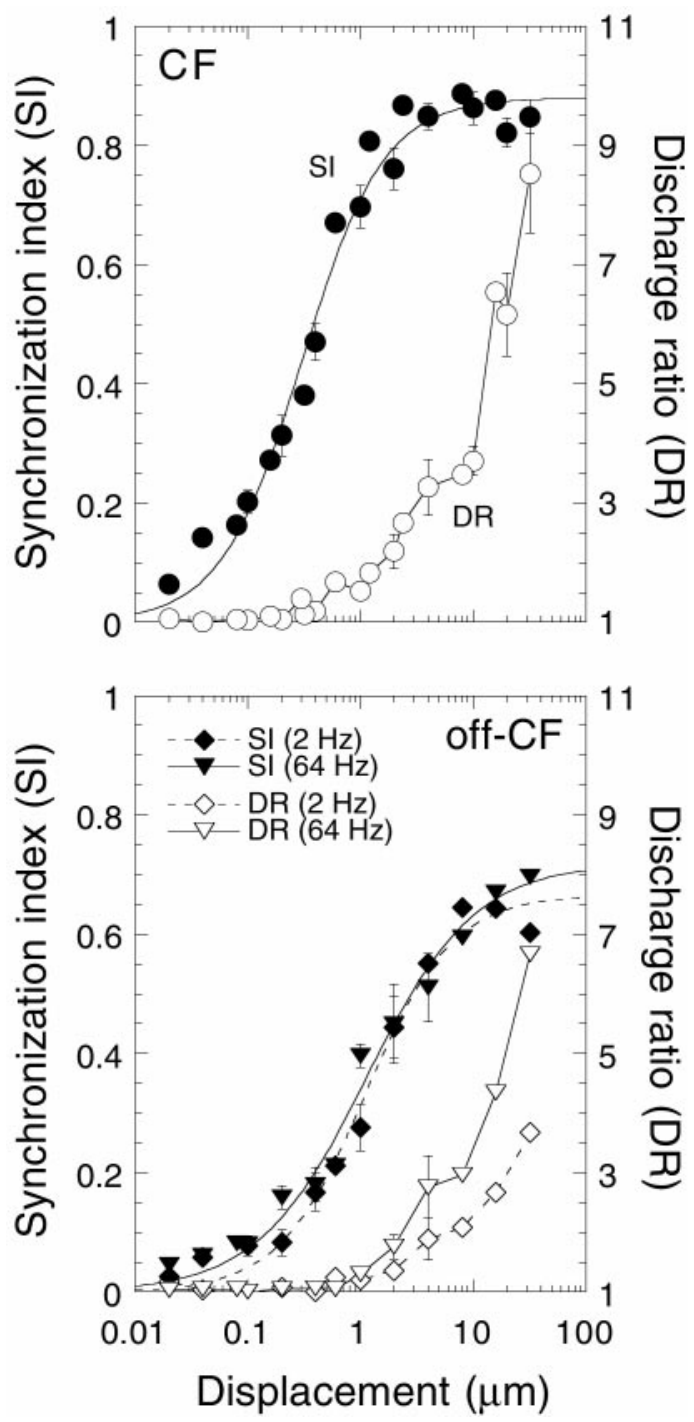

Figure 2. Both SI and DR increased with displacement. Data are summarized from 20 animals. Not all displacement levels were used in all experiments. Mean \pm SE are plotted for displacements with three or more data points. DR was calculated by dividing the discharge rate during stimulus presentation by the discharge rate immediately after the stimulus presentation. Sigmoidal curves were fit to the SI data using a least squares regression analysis.

of minutes after washing the peptide from the synapse. An example is shown in Figure 4.

We obtained data for the effects of CGRP on stimulus coding at concentrations ranging from 2 to $50 \mu \mathrm{M}$. In most cases, we used concentrations of 5 or $10 \mu \mathrm{M}$. Because each neuromast is innervated by two afferent nerve fibers, each of which responds $180^{\circ}$ out of phase with the other, we could only examine effects on SI in cases in which we could isolate the action potentials of these two fibers from one another. There were 17 such preparations. Two injections of CGRP at $2 \mu \mathrm{m}$ produced no effect. Only one injection was made at $50 \mu \mathrm{m}$. The 15 cases at concentrations of 5 $\mu \mathrm{m}$ and above are summarized below.

Perfusion with CGRP reversibly suppressed SI and lowered DR while increasing spontaneous discharge rate (Fig. 5). Peak effects for spontaneous rate, SI, and DR were generally observed 2-3 min after perfusion began. All responses recovered with 

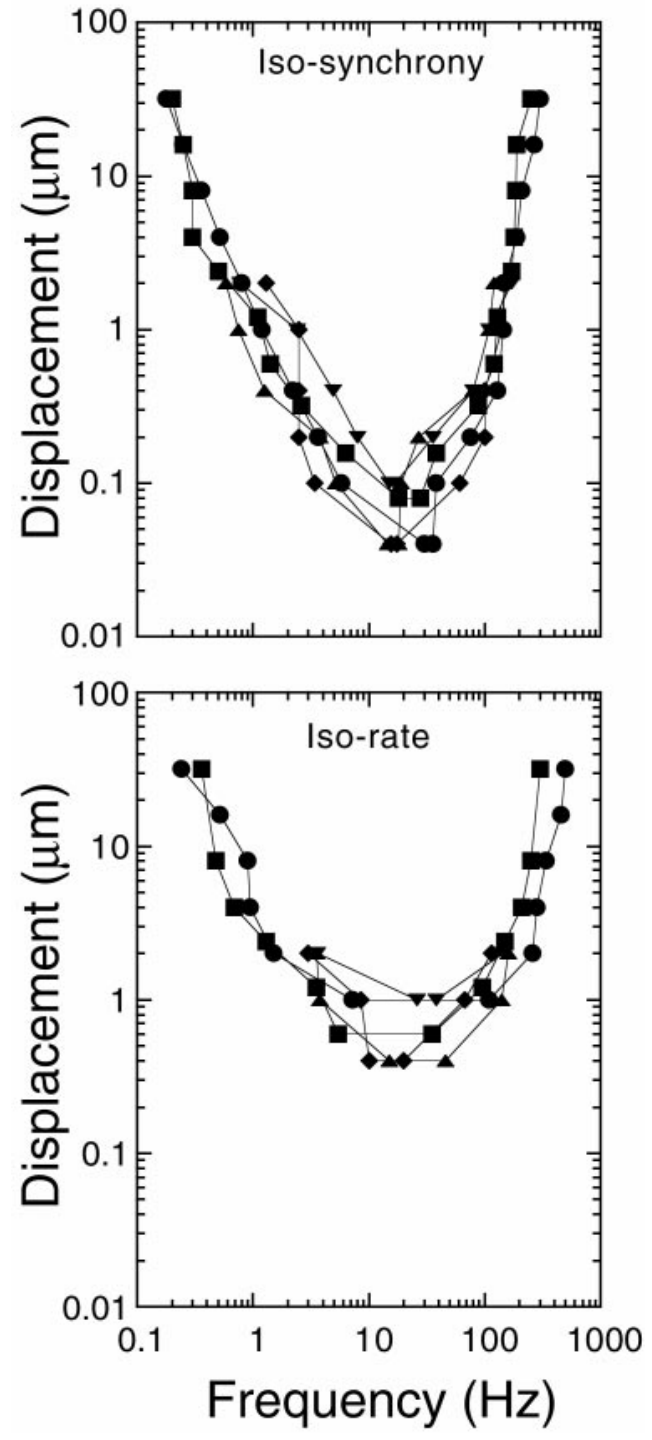

Figure 3. Threshold tuning curves for five fibers were generated from isodisplacement functions using SI (top) and DR (bottom) criterion levels for threshold. Threshold criteria for SI were displacements producing an SI of 0.15 . Threshold criteria for DR were displacements producing a DR of 1.25 . High (above $128 \mathrm{~Hz}$ ) and low (below $1 \mathrm{~Hz}$ ) frequency tails of the tuning curves are extrapolated from the isodisplacement functions by interpolation of the last two data points.

similar time courses. Mean \pm SE changes produced by CGRP at displacements $2 \mu \mathrm{m}$ or below (12 animals) in spontaneous rate, SI, and DR are $-39.1 \pm 5.5,-34.9 \pm 5.5$, and $-13.4 \pm 2.8 \%$, respectively.

Changes in the period histograms taken before and during GCRP application suggest that CGRP is decreasing the sensitivity of the preparation to mechanical displacement. The effects of CGRP on two different preparations are shown in Figure 6. The top and bottom panels, respectively, show effects of CGRP with low $(0.4 \mu \mathrm{m})$ and high $(2 \mu \mathrm{m})$ levels of cupular displacement. In both cases, the appearance is similar to that seen when the gain of the stimulus was reduced by $6 \mathrm{~dB}$ (insets in each panel). One difference, apparent in the top panel, is that CGRP increases the spontaneous rate around which the discharge is modulated. The

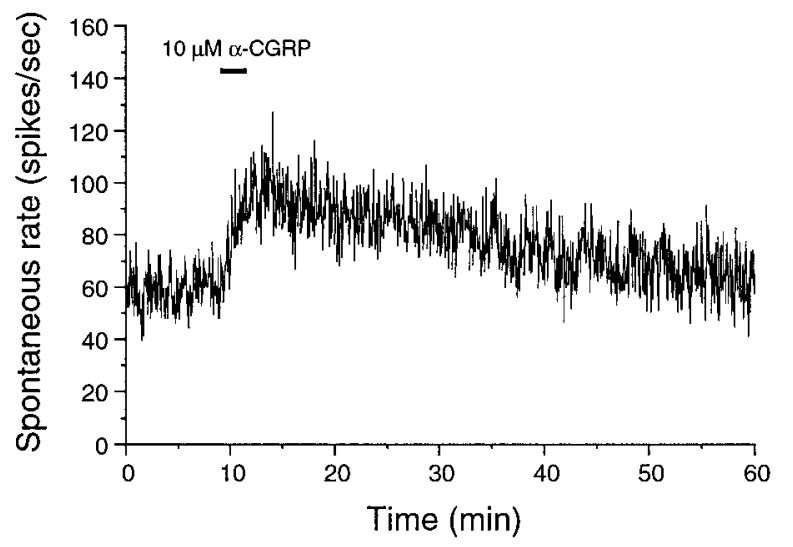

Figure 4. CGRP increased spontaneous discharge rate, an effect lasting long after CGRP was washed out. The preparation was continually perfused with a balanced salt solution. CGRP was administered at $10 \mu \mathrm{M}$ during the time indicated with the bar.
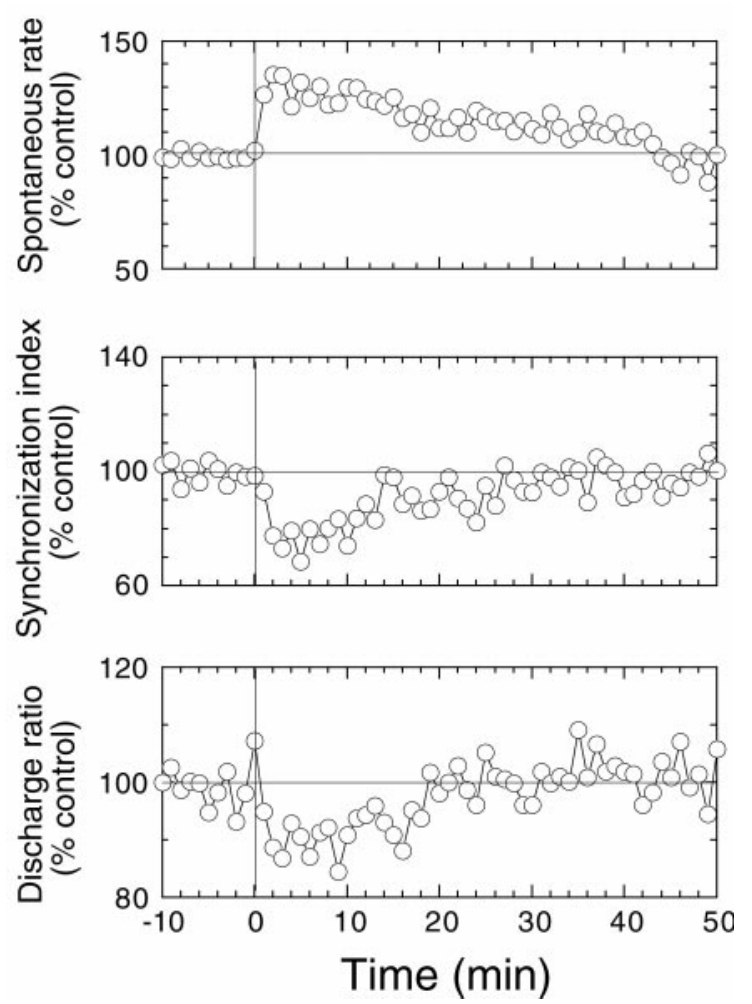

Figure 5. Time course of the change in spontaneous rate, SI, and DR with CGRP perfusion. CGRP was applied at time 0 at concentrations of 5-50 $\mu \mathrm{M}$. Each data point represents the average for 10 animals in which displacements were $2 \mu \mathrm{m}$ or smaller and responses were stable for $50 \mathrm{~min}$ or more. Data points for each variable were taken once per minute.

change in sensitivity during high-level stimulation, shown in the bottom panel of Figure 6, also demonstrates that CGRP decreases the response of the fiber to displacement levels that produce an increase in average rate.

The reduction in sensitivity to mechanical stimulation is most apparent when the displacement-SI function is plotted before and after CGRP (Fig. 7). These data, representing effects of CGRP on 15 different animals, are consistent with a simple shift in the displacement-SI function to the right by $\sim 10 \mathrm{~dB}$. 

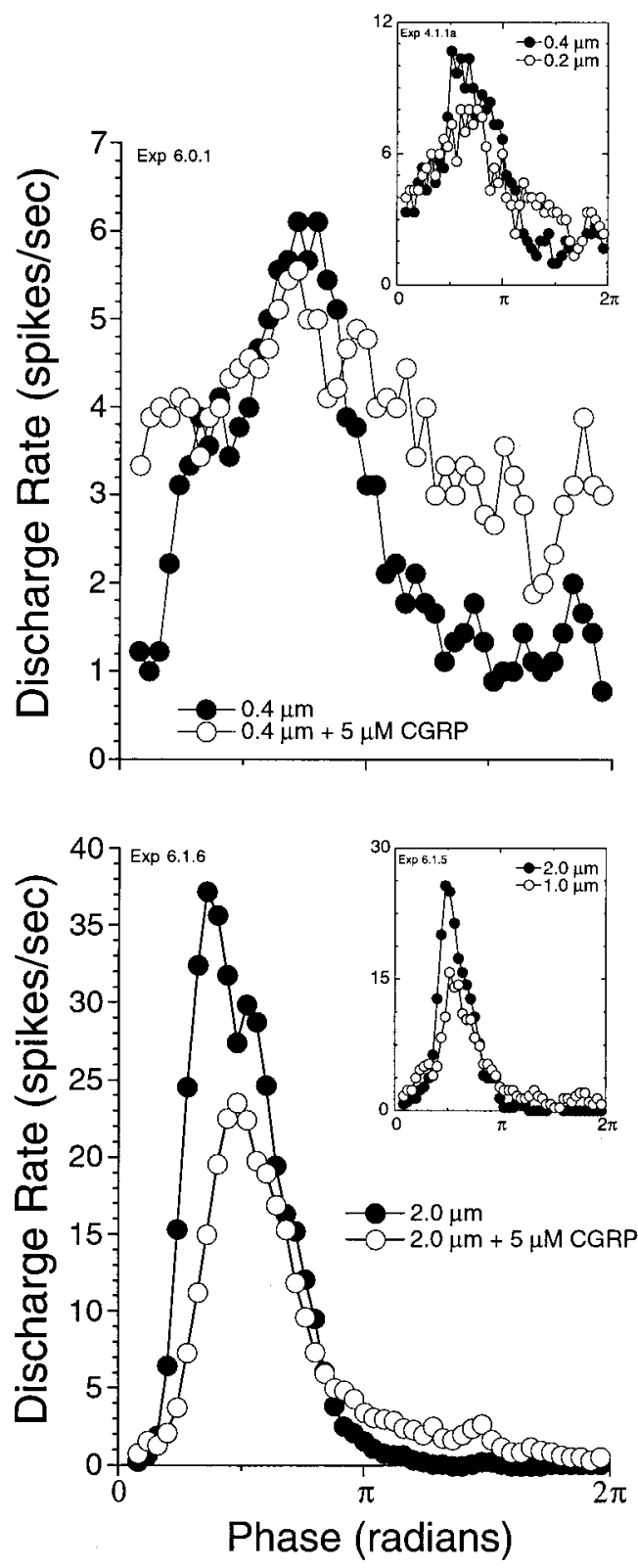

Figure 6. CGRP suppresses response to mechanical stimulation. Period histograms before (filled circles) and after (open circles) CGRP are plotted for two representative fibers. The fiber in the top was stimulated with a relatively low cupular displacement, whereas that in the bottom was stimulated with high displacement. Both fibers were stimulated at CF. For the fiber in the top, discharge rate was modulated around spontaneous without an overall increase in rate during stimulation. For the fiber in the bottom, displacements produced an increase in rate. Insets are examples (from a different fiber) of the change produced in the period histogram by lowering the gain of the stimulus by $6 \mathrm{~dB}$.

The response of these fibers to CGRP can be represented by assuming that CGRP decreases sensitivity of the fiber while increasing the spontaneous discharge rate. One way of simplistically visualizing the changes in response to displacement with CGRP is simulated in Figure 8, which shows the expected change, with CGRP, in the response to a tone burst for low-level displacements. Here we have simulated a $50 \%$ reduction in modulation depth with an increase in spontaneous rate of $30 \%$, typical of what we have observed.

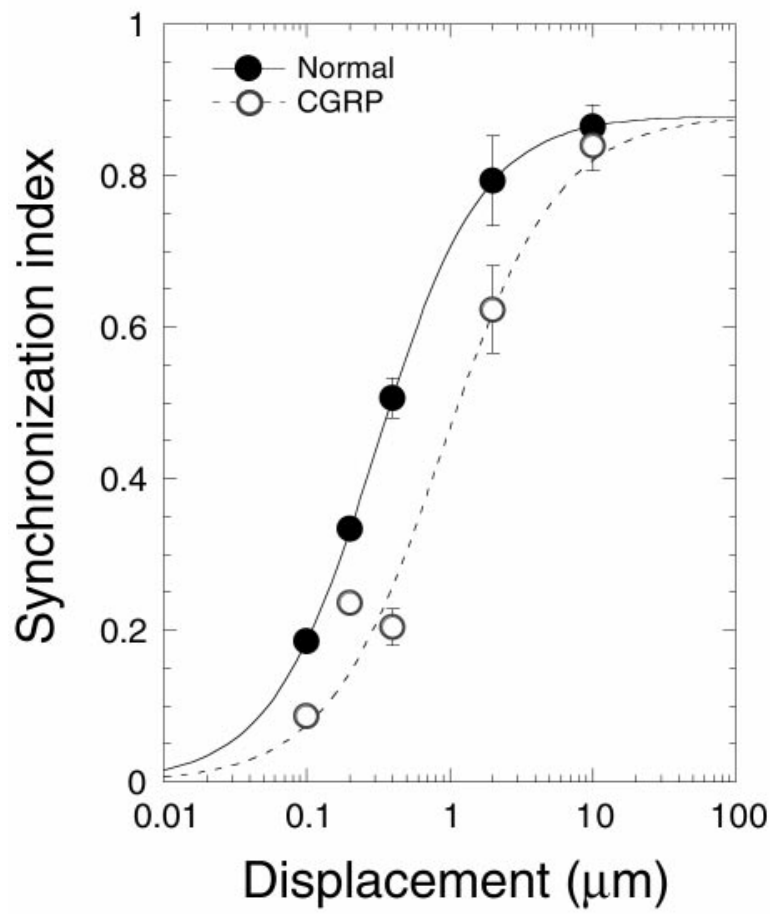

Figure 7. CGRP shifts the displacement-response function to higher displacement levels. Data (mean $\pm \mathrm{SE}$ ) taken before ( filled circles) and after (open circles) CGRP administration are plotted on the same axes. SI values before and after CGRP administrations were normalized to the sigmoidal curve from Figure 2. A sigmoidal curve was fit to all of the CGRP data (dashed line) by a least squares regression analysis. The curve was constrained to the normal maximum SI. There were three cases at 10 $\mu \mathrm{m}$, six cases at $2 \mu \mathrm{m}$, three cases at $0.4 \mu \mathrm{m}$, two cases at $0.2 \mu \mathrm{m}$, and one case at $0.1 \mu \mathrm{m}$.

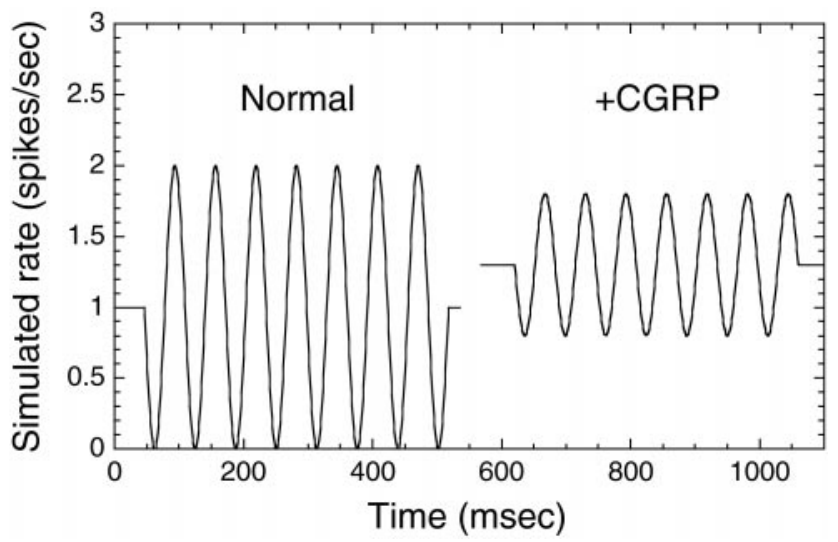

Figure 8. Our view of the effects of CGRP is conceptualized in this simulation of afferent discharge in response to a tone at which spontaneous rate is increased (30\%) and the depth of modulation is reduced $50 \%$.

\section{DISCUSSION}

\section{CGRP is an inhibitory efferent neurotransmitter}

This is the first report that suggests a functional role of CGRP, or any peptide, in efferent fibers innervating hair cell organs. CGRP suppressed responses of the lateral line organ to mechanical displacement. In the presence of CGRP, larger displacements of the cupula were required to produce the same response. This action suggests a function for CGRP as an efferent neurotransmitter that is strikingly similar to that of cholinergic efferent 
transmission in other hair cell organs. A shift to higher levels in the displacement-SI curve of $10 \mathrm{~dB}$ makes it comparable in magnitude with the effects of electrical stimulation of efferents in both the lateral line organ (Flock and Russell, 1976) and the mammalian cochlea (Gifford and Guinan, 1983). This suggests a significant role for CGRP in efferent modulation of the output of this mechanosensory organ.

The effects of CGRP differ from those of efferent stimulation in that cholinergically mediated efferent stimulation suppresses spontaneous discharge in the Xenopus lateral line organ (Russell, 1968; Sewell and Starr, 1991), whereas CGRP increases spontaneous discharge rate. This and several other observations suggest that the effects of CGRP are not mediated via the cholinergic receptor. First, in our in vitro preparation, the efferent nerve fibers have been cut and are not active. Second, the effects of CGRP on spontaneous discharge rate are evident, even when the effects of cholinergic antagonists block cholinergic efferent stimulation (Sewell and Starr, 1991). Finally, although the effects of CGRP appear to mimic those of acetylcholine, the only known direct interaction of CGRP with cholinergic transmission is a suppression of the cholinergic response (Giniatullin et al., 1999).

These differences between CGRP and acetylcholine may offer some advantages. An increase in rate with CGRP may offset the decrease in rate associated with cholinergic efferent stimulation. Spontaneous rates in this preparation are low and stochastic, which may make detection of temporal information content in the signal more difficult. CGRP decreases the depth of modulation, which will increase threshold for detecting signals. However, the increase in spontaneous rate by CGRP could effectively decrease the noise to provide a more secure transfer of temporal information despite the decrease in sensitivity. Another advantage, illustrated by Boyle and Highstein (1990) and first noted by Goldberg and Fernandez (1980), is that increasing the spontaneous rate ensures that the modulation is not clipped at reductions of rate to near zero. Thus, CGRP makes the receptor a better transducer for large-amplitude motions.

\section{Cellular mechanisms of CGRP-induced changes in discharge patterns}

Our previous work showed that the increase in spontaneous discharge rate produced by CGRP was associated with an increase in the rate of occurrence of EPSPs measured in the afferent nerve fibers (Sewell and Starr, 1991). This observation suggested that CGRP was increasing the probability of vesicular transmitter release from the hair cell. In the present report, we demonstrate that the suppression of stimulus-evoked responses by CGRP was similar to that expected of acetylcholine, a neurotransmitter that is colocalized with CGRP in many efferent terminals (Ohno et al., 1991; Vetter et al., 1991; Roberts et al., 1994; Safieddine et al., 1997). As detailed below, an increase in intracellular calcium by CGRP might produce both an acetylcholinelike suppression of stimulus-evoked responses and an increase in spontaneous discharge rate.

It is the local increase in intracellular calcium concentration $\left[\mathrm{Ca}^{2+}\right]_{\mathrm{i}}$ that generates the effects of acetylcholine in the hair cell [for review, see Fuchs (1996)]. The $\alpha-9$ cholinergic receptor is directly permeable to calcium (Elgoyhen et al., 1994), and increases in $\left[\mathrm{Ca}^{2+}\right]_{\mathrm{i}}$ mediated by acetylcholine are highly localized near the synapse. The increased $\left[\mathrm{Ca}^{2+}\right]_{\mathrm{i}}$ interacts with calciumactivated potassium channels $\left(\mathrm{K}_{\mathrm{Ca}}\right)$ to hyperpolarize the hair cell and to shunt the transduction current (Art et al., 1984). Cholinergic efferent stimulation suppresses spontaneous discharge rate, indicating that the calcium entering via nicotinic receptors is not sufficient to increase the rate of release of transmitter. Instead, hyperpolarization of the cell dominates the effect on transmitter release. Like outer hair cells of the mammal and short hair cells of the chick, hair cells in Xenopus have synaptic cisternae opposite the efferent terminals (Flock, 1967). One function of these cisternae is to constrain calcium influx through the cholinergic receptor to a location near the efferent synapse (Martin and Fuchs, 1992).

The CGRP receptor, on the other hand, is a G-protein-coupled receptor, which is more likely to produce changes in calcium at a distance (Ishikawa et al., 1993; Aiyar et al., 1999; Huang et al., 1999). If CGRP were increasing intracellular calcium, it could produce both an acetylcholine-like suppression and an increase in discharge rate. Martin and Fuchs (1992) have calculated that $\mathrm{K}_{\mathrm{Ca}}$ channels at the cholinergic synapse are activated by calcium concentrations in the low micromolar range. This may not be too different from the standing calcium concentration at the synapse that drives spontaneous discharge rate (Roberts, 1994). Thus, a relatively small change in calcium concentration may both increase spontaneous rate and activate $\mathrm{K}_{\mathrm{Ca}}$ channels to produce acetylcholine-like suppression of responses to displacement.

\section{Comparison with efferent activation in other systems}

The action of CGRP to decrease gain while increasing spontaneous rate is similar to an action described for efferent stimulation in the vestibular system of squirrel monkey (Goldberg and Fernandez, 1980) and in the toadfish (Boyle and Highstein, 1990). Our results raise the question of whether any of those effects might be attributable to CGRP. In the squirrel monkey, efferent stimulation increases discharge rate with both a fast and a slow component. Although it is tempting to attribute the slow component, which persists for tens of seconds after efferent stimulation, to a CGRP second-messenger-mediated effect, it should be noted that, in the cochlea, slow effects with similar time courses are undoubtedly attributable to activation of the cholinergic receptor (Sridhar et al., 1995).

\section{Implications for understanding efferent activation through CGRP of the mammalian cochlea}

The location of CGRP in cholinergic efferents that terminate on hair cells of the lateral line organ is comparable with those CGRP-containing lateral olivocochlear efferents that terminate on the inner hair cells (IHCs) in the mammalian cochlea. Although these lateral olivocochlear efferents are often described as terminating on the radial afferent fibers, there are a significant number of efferent terminals on the IHCs (Liberman, 1980; Liberman et al., 1990). The cholinergic synapses on the IHC contain the same $\alpha-9$ nicotinic receptors seen on hair cells of the lateral line organ. It is plausible that CGRP has the same action on inner hair cells as it does in the lateral line organ: to increase spontaneous transmitter release from the IHCs while decreasing their sensitivity to sound.

\section{REFERENCES}

Adams JC, Mroz EA, Sewell WF (1987) A possible neurotransmitter role for CGRP in a hair-cell sensory organ. Brain Res 419:347-351.

Aiyar N, Disa J, Stadel JM, Lysko PG (1999) Calcitonin gene-related peptide receptor independently stimulates $3^{\prime}, 5^{\prime}$-cyclic adenosine monophosphate and $\mathrm{Ca}^{2+}$ signaling pathways. Mol Cell Biochem 197:179-185.

Art JJ, Fettiplace R, Fuchs PA (1984) Synaptic hyperpolarization and inhibition of turtle cochlear hair cells. J Physiol (Lond) 56:525-550.

Boyle R, Highstein SM (1990) Efferent vestibular system in the toadfish: 
action upon horizontal semicircular canal afferents. J Neurosci 10:1570-1582.

Elepfandt A (1988) Processing of wave patterns in the lateral line system parallels to auditory processing. Acta Biol Hung 39:251-265.

Elgoyhen AB, Johnson DS, Boulter J, Vetter DE, Heinemann S (1994) Alpha 9: an acetylcholine receptor with novel pharmacological properties expressed in rat cochlear hair cells. Cell 79:705-715.

Flock $\AA$ (1967) Ultrastructure and function in the lateral line organs. In: Lateral line detectors (Cahn P, ed), pp 163-197. Bloomington, IN: Indiana UP.

Flock $\AA$, Lam DM (1974) Neurotransmitter synthesis in inner ear and lateral line sense organs. Nature 249:142-144.

Flock $\AA$, Russell I (1976) Inhibition by efferent nerve fibres: action on hair cells and afferent synaptic transmission in the lateral line canal organ of the burbotr lota lota. J Physiol (Lond) 257:45-62.

Fritzsch B (1989) Diversity and regression in the amphibian lateral line and electrosensory system. In: The mechanosensory lateral line: neurobiology and evolution (Coombs S, Görner P, Münz H, eds), pp 99-114. New York: Springer.

Fuchs PA (1996) Synaptic transmission at vertebrate hair cells. Curr Opin Neurobiol 6:514-519.

Gifford ML, Guinan Jr JJ (1983) Effects of crossed-olivocochlear-bundle stimulation on cat auditory nerve fiber responses to tones. J Acoust Soc Am 74:115-123.

Giniatullin R, Di Angelantonio S, Marchetti C, Sokolova E, Khiroug L, Nistri A (1999) Calcitonin gene-related peptide rapidly downregulates nicotinic receptor function and slowly raises intracellular $\mathrm{Ca}^{2+}$ in rat chromaffin cells in vitro. J Neurosci 19:2945-2953.

Goldberg JM, Fernandez C (1980) Efferent vestibular system in the squirrel monkey: anatomical location and influence on afferent activity. J Neurophysiol 43:986-1025.

Görner P (1967) Independence of afferent activity from efferent activity in the lateral line organ of Xenopus laevis Daudin. In: Lateral line detectors (Cahn P, ed), pp 199-214. Bloomington, IN: Indiana UP.

Harris GG, Milne DC (1966) Input-output characteristics of the lateralline sense organs of Xenopus laevis. J Acoust Soc Am 40:32-42.

Hellmann B, Fritzsch B (1996) Neuroanatomical and histochemical evidence for the presence of common lateral line and inner ear efferents and of efferents to the basilar papilla in a frog, Xenopus laevis. Brain Behav Evol 47:185-194.

Huang MH, Knight III PR, Izzo Jr JL (1999) $\mathrm{Ca}^{2+}$-induced $\mathrm{Ca}^{2+}$ release involved in positive inotropic effect mediated by CGRP in ventricular myocytes. Am J Physiol 276:R259-R264.

Ishikawa M, Ouchi Y, Orimo H (1993) Effect of calcitonin gene-related peptide on cytosolic free $\mathrm{Ca}^{2+}$ level in vascular smooth muscle. Eur J Pharmacol 246:121-128.

Johnson DH (1980) The relationship between spike rate and synchrony in responses of auditory-nerve fibers to single tones. J Acoust Soc Am 68:1115-1122.

Kroese AB, Van der Zalm JM, Van den Bercken J (1978) Frequency response of the lateral-line organ of Xenopus laevis. Pflügers Arch 375:167-175.
Liberman MC (1980) Efferent synapses in the inner hair cell area of the cat cochlea: an electron microscopic study of serial sections. Hear Res 3:189-204.

Liberman MC, Dodds LW, Pierce S (1990) Afferent and efferent innervation of the cat cochlea: quantitative analysis with light and electron microscopy. J Comp Neurol [Erratum 304:341] 301:443-460.

Martin AR, Fuchs PA (1992) The dependence of calcium-activated potassium currents on membrane potential. Proc R Soc Lond B Biol Sci 250:71-76.

Ohno K, Takeda N, Yamano M, Matsunaga T, Tohyama M (1991) Coexistence of acetylcholine and calcitonin gene-related peptide in the vestibular efferent neurons in the rat. Brain Res 566:103-107.

Roberts BL, Maslam S, Los I, Van der Jagt B (1994) Coexistence of calcitonin gene-related peptide and choline acetyltransferase in eel efferent neurons. Hear Res 74:231-237.

Roberts WM (1994) Localization of calcium signals by a mobile calcium buffer in frog saccular hair cells. J Neurosci 14:3246-3262.

Russell IJ (1968) Influence of efferent fibres on a receptor. Nature 219:177-178

Russell IJ (1971) The pharmacology of efferent synapses in the lateralline system of Xenopus laevis. J Exp Biol 54:643-658.

Safieddine S, Prior AM, Eybalin M (1997) Choline acetyltransferase, glutamate decarboxylase, tyrosine hydroxylase, calcitonin gene-related peptide and opioid peptides coexist in lateral efferent neurons of rat and guinea-pig. Eur J Neurosci 9:356-367.

Sewell WF, Mroz EA (1987) Neuroactive substances in inner ear extracts. J Neurosci 7:2465-2475.

Sewell WF, Starr PA (1991) Effects of calcitonin gene-related peptide and efferent nerve stimulation on afferent transmission in the lateral line organ. J Neurophysiol 65:1158-1169.

Shelton PM (1970) The lateral line system at metamorphosis in Xenopus laevis (Daudin). J Embryol Exp Morphol 24:511-524.

Shigemoto T, Ohmori H (1990) Muscarinic agonists and ATP increase the intracellular $\mathrm{Ca}^{2+}$ concentration in chick cochlear hair cells. J Physiol (Lond) 420:127-148.

Sliwinska-Kowalska M, Parakkal M, Schneider ME, Fex J (1989) CGRP-like immunoreactivity in the guinea pig organ of Corti: a light and electron microscopy study. Hear Res [Erratum 43:93] 42:83-95.

Sridhar TS, Liberman MC, Brown MC, Sewell WF (1995) A novel cholinergic "slow effect" of efferent stimulation on cochlear potentials in the guinea pig. J Neurosci 15:3667-3678.

Takeda N, Doi K, Mori N, Yamazaki H, Tohyama M, Matsunaga T (1987) Localization and fine structure of calcitonin gene-related peptide (CGRP)-like immunoreactive nerve fibres in the organ of Corti of guinea pigs by immunohistochemistry. Acta Otolaryngol (Stockh) 103:567-571.

Vetter DE, Adams JC, Mugnaini E (1991) Chemically distinct rat olivocochlear neurons. Synapse 7:21-43.

Wackym, PA Micevych, P Ward P, (1990) Immunoelectron microscopy of the human inner ear. Laryngoscope 100:447-454. 